\title{
Sinonasal mucosal melanoma: Molecular profile and therapeutic implications from a series of 32 cases
}

\author{
Mario Turri-Zanoni, MD, ${ }^{1}$ Daniela Medicina, MS, ${ }^{2}$ Davide Lombardi, MD, ${ }^{1}$ Marco Ungari, MD, ${ }^{2}$ Piera Balzarini, MS, ${ }^{2}$ Cristina Rossini, B.Tech, ${ }^{2}$ \\ Wilma Pellegrini, B.Tech, ${ }^{2}$ Paolo Battaglia, MD, ${ }^{3}$ Carlo Capella, MD, ${ }^{4}$ Paolo Castelnuovo, MD, ${ }^{3}$ Gabriele Palmedo, MD, ${ }^{5}$ Fabio Facchetti, MD, PhD, ${ }^{2}$ \\ Heinz Kutzner, MD, ${ }^{5}$ Piero Nicolai, MD, ${ }^{1}$ William Vermi, MD ${ }^{2,6 *}$ \\ ${ }^{1}$ Department of Otorhinolaryngology, University of Brescia, Brescia, Italy, ${ }^{2}$ Department of Pathology, University of Brescia, Brescia, Italy, ${ }^{3}$ Department of Otorhinolaryngology, \\ University of Insubria, Varese, Italy, ${ }^{4}$ Department of Pathology, University of Insubria, Varese, Italy, ${ }^{5}$ Dermatohistopathologische Gemeinschaftspraxis, Friedrichshafen, Germany, \\ ${ }^{6}$ Department of Pathology and Immunology, Washington University School of Medicine, St. Louis, Missouri.
}

Published online in Wiley Online Library (wileyonlinelibrary.com). DOI 10.1002/hed.23079

\begin{abstract}
Background. Primary sinonasal mucosal melanomas are aggressive tumors with a poor clinical control by current treatments, raising the urgent need of novel strategies.

Methods. By fluorescence in situ hybridization (FISH), direct sequencing, and immunohistochemistry, we investigate the spectrum of molecular abnormalities in a cohort of 32 cases of primary sinonasal mucosal melanomas.

Results. We found that all primary sinonasal mucosal melanomas lack BRAF V600E mutation; in addition, they are characterized by somatic mutations of NRAS $(22 \%)$ and KIT $(12.5 \%)$, together with amplification of RREB1 (100\%) and loss of MYB (76\%). The large majority of cases showed KIT protein expression (96.9\%). Among tumor suppressor
\end{abstract}

genes, primary sinonasal mucosal melanomas showed loss of PTEN (48.1\%) and p16/INK4a (55.2\%). All tested cases showed expression of pAkt and pErk, suggesting a combined activation of PI3K/Akt and RASmitogen-activated protein kinase (MAPK) pathways.

Conclusions. This molecular fingerprint strongly argues against the clinical efficacy of BRAF-inhibitors, but could candidate primary sinonasal mucosal melanomas to therapeutic strategies targeting RAS and KIT mutations or inhibiting PI3K-Akt-mTOR pathway. Head Neck 00: 000-000, 2012

KEY WORDS: sinonasal melanoma, NRAS, KIT, RAS-MAPK pathway, PI3K/Akt pathway

\section{INTRODUCTION}

Melanocytes acquire step-wise abnormalities of oncogenes and tumor suppressor genes during transformation and neoplastic progression. ${ }^{1}$ Somatic mutations of oncogenes such as BRAF, NRAS, HRAS, and GNAQ represent early events in the development of melanocytic tumors, primarily by inducing cell proliferation via mitogen-activated protein kinase (MAPK) pathway activation. Abnormalities in tumor suppressor genes contribute to the dysregulation of additional pathways implicated in melanoma progression, including p16-CDK4-RB, ARF-p53, and PI3K-Akt. ${ }^{2}$ Recent studies have shown that the frequency of these molecular events are variably distributed among melanoma subgroups, thus supporting the notion that melanoma is a molecularly heterogeneous disease. ${ }^{3}$

${ }^{*}$ Corresponding author: W. Vermi, Department of Pathology, University of Brescia, Spedali Civili di Brescia, P.le Spedali Civili, 1, 25123, Brescia, Italy. E-mail: vermi@med.unibs.it

Contract grant sponsor: Fondazione Berlucchi (Brescia, Italy) and by Regione Lombardia (Progetto di Ricerca Indipendente), to Fabio Facchetti. Cristina Rossini is supported by "Borsa di studio Prof. Roberto Tosoni" (Garda Vita, BCC del Garda).
For example, melanomas arising on skin intermittently exposed to the sun (nonchronic sun-damage melanoma) are characterized by activating mutations of BRAF $(66 \%)^{4}$ and NRAS $(15 \% \text { to } 20 \%)^{5}$ with loss of PTEN expression, ${ }^{6}$ whereas melanomas arising from mucosal membrane, acral sites, and chronic sun-damaged skin (chronic sun-damage melanoma) harbor BRAF mutations less frequently and show a variable frequency of KIT mutations, ${ }^{7}$ together with cyclin D1 $(C C N D 1)^{8}$ or cyclindependent kinase 4 amplifications. ${ }^{9}$ Remarkably, all these advances have led to the creation of a "molecular disease model" for melanoma that classifies individual tumors into molecular subtypes with proposed treatment guidelines for each. ${ }^{10}$

In recent years, efforts have been devoted to identify driver genetic events leading to transformation of mucosal melanocytes. Primary sinonasal tract mucosal melanomas are 1 of the most common mucosal melanomas, characterized by a very aggressive biologic behavior. ${ }^{1-13}$ In this study, we took advantage of a homogenous cohort of 32 primary sinonasal tract mucosal melanomas to identify molecular abnormalities relevant to the biology of this melanoma subtype that could have also implications for the development of tailored targeted therapies. 


\section{MATERIALS AND METHODS}

\section{Patients and tissues}

Thirty-two cases of primary sinonasal mucosal melanomas diagnosed between May 2003 and August 2010 were included. Tissue blocks were retrieved from the Department of Pathology of 2 institutions (Brescia and Varese Hospital, Italy). Diagnosis was based on clinical presentation and pathology findings. Follow-up was available for all cases. The study on human tissue samples has been conducted in compliance with the Helsinki Declaration and with policies approved by the local ethics board (Spedali Civili di Brescia).

\section{Immunohistochemistry}

Tissue sections from formalin-fixed, paraffin-embedded blocks were used for immunohistochemical staining. The panel of primary antibodies included MART-1 (mouse, dilution 1:50; Dako Cytomation, Glostrup Denmark), HMB45 (mouse, dilution 1:50; Dako Cytomation), tyrosinase (mouse, dilution 1:50; NeoMarkers, Fremont, CA), CD117 (rabbit, dilution 1:50; Dako Cytomation), cyclin D1 (rabbit, dilution 1:20; Thermo Scientific, Fremont, CA), p16INK4a (MTM Heidelberg), PTEN (rabbit, dilution 1:100; Cell Signaling Technology), phospho-Akt (Ser473) pAkt (rabbit, dilution 1:30 overnight; Cell Signaling Technology), phospho-p44/42 MAPK (Thr202/ Tyr204) pERK (rabbit, dilution 1:250; Cell Signaling Technology). Upon appropriate antigen retrieval, reactivity was revealed using the Real EnVision Mouse/RabbitHRP (Dako) or NovoLink Polymer Detection System (Novocastra) followed by DAB. Immunohistochemical scores were assessed independently by 2 pathologists (M.U. and W.V.), according to the percentage of positive tumor cells (score $0=$ absence of positive cells; score 1 $=1 \%$ to $25 \%$ of positive cells; score $2=25 \%$ to $50 \%$ of positive cells; score $3=50 \%$ to $75 \%$ of positive cells; and score $4=>75 \%$ of positive cells). Digital images taken using the Olympus BX60 microscope were captured using a DP-70 Olympus digital camera and processed using Analysis Image Processing software (Olympus).

\section{Melanoma multicolor and 9p21 fluorescence in situ hybridization}

Melanoma multicolor fluorescence in situ hybridization (FISH) (Abbott, Germany) and dual color FISH of the 9p21 region were performed on 27 mucosal melanomas.

For melanoma multicolor FISH and dual color FISH of the 9p21 region, each series was completed using 1 negative control (nevus) and 1 positive control (melanoma). For detection of amplifications or deletions of the RREB 1, MYB, and CCND1 genes in relation to the centromere of chromosome 6 , the melanoma FISH probe mix (Abbott, Germany) was used consisting of 4 probes: RREB1 on $6 \mathrm{p} 25, M Y B$ on $6 \mathrm{q} 23, C C N D 1$ on $11 \mathrm{q} 13$, and CEP6 (centromeric probe of chromosome 6). For the detection of a deletion of $9 \mathrm{p} 21$, a directly spectrum orange (9p21), and spectrum green (centromeric probe of chromosome 9) labeled probe (Abbott, Wiesbaden, Germany) was used for hybridization.
FISH with the melanoma multicolor and the 9p21 dual color probe was performed on $3-\mu \mathrm{M}$ sections of formalinfixed, paraffin-embedded tissue after baking at $56^{\circ} \mathrm{C}$ for 16 hours, followed by deparaffinization with xylene and dehydration with ethanol. All tissue sections were pretreated with $1 \mathrm{X} \mathrm{SSC}$ at $80^{\circ} \mathrm{C}$ for 35 minutes and digested with pepsin at $37^{\circ} \mathrm{C}$ for 15 minutes. For hybridization with the 9p21, probe tissue sections were pretreated with a $30 \%$ solution of sodium bisulfite and digested with proteinase $\mathrm{K}$ following the instructions of the suppliers (QBiogene, Heidelberg, Germany). Digestion times were optimized on a case-by-case basis. After a second dehydration step, probes were applied to the tissue sections, and slides were cover-slipped and sealed with rubber cement. Sections were heat-denatured and hybridized at $37^{\circ} \mathrm{C}$ for 16 hours. After stringent washing, sections were counterstained with diamidino-phenylindole I in mounting medium (1000 ng/mL; Abbott, Wiesbaden, Germany).

A minimum of 30 non-overlapping intact nuclei were assessed for the presence of amplified and deleted signals. A deletion was defined as a lower number of signals compared to the CEP6 signals. Amplification was defined as 3 or more signals. Nuclei with the appropriate signals were digitally photographed with a monochrome RT3 CCD camera (Diagnostic Instruments, Sterling Heights, MI) connected to a Zeiss Axioplan 2 microscope (Zeiss, Oberkochen, Germany) using a HBO103 lamp and the appropriate filters (spectrum red, spectrum gold, spectrum green, spectrum aqua, and 4',6-diamino-2-phenylindole) for the 5 fluorescence dyes (Zeiss). Reconstruction into a single image with superimposed blue, red, gold, and green pseudocolors was accomplished using SPOT software (Visitron Systems, Puchheim, Germany). The cutoff levels for the 4 probes were calculated as described in the instructions of the supplier and after Gerami et $\mathrm{al}^{14}$ in 2009.

For CCND1 FISH, slides were deparaffinized, dehydrated in $100 \%$ ethanol, and dried at $45^{\circ} \mathrm{C}$. Sections were immersed in $\mathrm{HCl}(0.2 \mathrm{~N})$ for 20 minutes and then incubated in sodium thiocyanate at $81^{\circ} \mathrm{C}$ for 30 minutes. Slides were placed in pepsin solution (2500-3000 U/mg, lyophilized) at $37^{\circ} \mathrm{C}$ for 40 minutes and air-dried. The probe LSI Cyclin D1/CEP11 (Vysis) was applied and sealed under a cover slip with rubber cement, and incubated at $73^{\circ} \mathrm{C}$ for 5 minutes to denature DNA followed by hybridization in a humidified chamber at $37^{\circ} \mathrm{C}$ overnight. The following day, samples were incubated in post-hybridization solution ( $2 \mathrm{X} \mathrm{SSC} / 0.3 \% \mathrm{NP}-40)$ at $73^{\circ} \mathrm{C}$ for 2 minutes. Finally, they were air dried and counterstained with diamidino-phenylindole I/Antifade solution. Tumor samples were examined with an epifluorescent microscope (Nikon, Eclipse 90I). In each sample, signals were counted in a total of 100 non-overlapping tumor-cell nuclei. The mean signal number of the cyclin D1 gene as well as CEP was calculated, and the ratio determined.

\section{DNA extraction and direct sequencing}

Formalin-fixed, paraffin-embedded tissue blocks were reviewed for quality control and tumor content. A representative block containing more than $50 \%$ of malignant cells was available for each case. Genomic DNA was 
TABLE 1. Clinical and pathological findings of primary sinonasal mucosal melanomas.

\begin{tabular}{|c|c|c|c|c|c|c|c|c|c|c|c|c|c|}
\hline Case & Sex & $\begin{array}{c}\text { Age, } \\
y\end{array}$ & Site & Histology & $\begin{array}{l}\text { Previous } \\
\text { treatment }\end{array}$ & Treatment & $\begin{array}{c}\text { TNM } \\
\text { classification }\end{array}$ & $\begin{array}{c}\text { Adjuvant } \\
\text { therapy }\end{array}$ & $\begin{array}{l}\text { Relapse } \\
\text { site }\end{array}$ & $\begin{array}{l}\text { Time to } \\
\text { relapse, mo }\end{array}$ & $\begin{array}{c}\text { Relapse } \\
\text { treatment }\end{array}$ & $\begin{array}{c}\text { Follow-up, } \\
\text { mo }\end{array}$ & Status \\
\hline \#1 & $\mathrm{F}$ & 68 & $\mathrm{M}$ & E & - & CFR & $\mathrm{T}_{3} \mathrm{~N}_{0} \mathrm{M}_{0}$ & - & $M^{B}$ & 2 & - & 7 & DOD \\
\hline \#2 & $M$ & 63 & $\mathrm{~N}-\mathrm{E}$ & $\mathrm{E}$ & - & CFR & $\mathrm{T}_{3} \mathrm{~N}_{0} \mathrm{M}_{0}$ & RT & - & - & NA & 94 & NED \\
\hline \#3 & $\mathrm{M}$ & 77 & $M$ & $\mathrm{E}$ & - & $\mathrm{CHT}$ & $\mathrm{T}_{3} \mathrm{~N}_{0} \mathrm{M}_{1}$ & NA & $M^{L}$ & 11 & $\mathrm{CHT}$ & 13 & DOD \\
\hline$\# 4$ & $\mathrm{~F}$ & 88 & $\mathrm{~N}-\mathrm{E}$ & E & - & ERTC & $\mathrm{T}_{3} \mathrm{~N}_{0} \mathrm{M}_{0}$ & - & $\mathrm{T}$ & 24 & $\mathrm{~S}, \mathrm{RT}$ & 59 & DOD \\
\hline$\# 5$ & $M$ & 64 & $M$ & E, S & - & CFR & $\mathrm{T}_{4 \mathrm{a}} \mathrm{N}_{0} \mathrm{M}_{0}$ & - & $T, M^{B, L}$ & 6 & - & 9 & DOD \\
\hline \#6 & $\mathrm{F}$ & 71 & $\mathrm{~N}-\mathrm{E}$ & E & - & ERTC & $\mathrm{T}_{3} \mathrm{~N}_{0} \mathrm{M}_{0}$ & - & $\mathrm{T}, \mathrm{M}^{\mathrm{SK}, \mathrm{L}}$ & 17 & $\mathrm{~S}, \mathrm{CHT}$ & 79 & AWD \\
\hline$\# 7$ & $\mathrm{~F}$ & 67 & $\mathrm{~N}-\mathrm{E}$ & E & - & CER & $\mathrm{T}_{3} \mathrm{~N}_{0} \mathrm{M}_{0}$ & - & $\mathrm{T}, \mathrm{M}^{\mathrm{LI}}$ & 15 & $\mathrm{~S}, \mathrm{RT}$ & 19 & DOD \\
\hline$\# 8$ & $\mathrm{~F}$ & 76 & $\mathrm{~N}-\mathrm{E}$ & $\mathrm{E}$ & - & CER & $\mathrm{T}_{3} \mathrm{~N}_{0} \mathrm{M}_{0}$ & - & $\mathrm{M}^{\mathrm{B}, \mathrm{L}}$ & 22 & - & 25 & DOD \\
\hline$\# 9$ & $\mathrm{~F}$ & 85 & $\mathrm{~N}-\mathrm{E}$ & $\mathrm{E}$ & - & CER & $\mathrm{T}_{3} \mathrm{~N}_{0} \mathrm{M}_{0}$ & - & $\mathrm{T}, \mathrm{M}^{\mathrm{B}, \mathrm{L}}$ & 18 & - & 20 & DOD \\
\hline$\# 10$ & $\mathrm{~F}$ & 70 & $\mathrm{~N}-\mathrm{E}$ & $\mathrm{E}$ & - & CFR & $\mathrm{T}_{4 \mathrm{a}} \mathrm{N}_{0} \mathrm{M}_{0}$ & - & $\mathrm{N}, \mathrm{M}^{\mathrm{G}}$ & 22 & $\mathrm{~S}, \mathrm{RT}$ & 34 & DOD \\
\hline \#11 & $\mathrm{F}$ & 80 & $\mathrm{~N}-\mathrm{E}$ & E & $\mathrm{S}$ & ERTC & $\mathrm{T}_{3} \mathrm{~N}_{0} \mathrm{M}_{0}$ & - & - & - & NA & 52 & NED \\
\hline$\# 12$ & $\mathrm{~F}$ & 56 & $\mathrm{~N}-\mathrm{E}$ & $\mathrm{E}$ & - & CER & $\mathrm{T}_{4 \mathrm{~b}} \mathrm{~N}_{1} \mathrm{M}_{0}$ & CHT & $\mathrm{T}, \mathrm{N}$ & 5 & - & 9 & DOD \\
\hline$\# 13$ & $M$ & 81 & $M$ & $\mathrm{E}$ & - & CFR & $\mathrm{T}_{3} \mathrm{~N}_{0} \mathrm{M}_{0}$ & - & $\mathrm{N}, \mathrm{M}^{\mathrm{AG}}$ & 29 & - & 29 & DOD \\
\hline$\# 14$ & $\mathrm{M}$ & 60 & $\mathrm{~N}-\mathrm{E}$ & $\mathrm{E}$ & $S$ & ERTC & $\mathrm{T}_{3} \mathrm{~N}_{0} \mathrm{M}_{0}$ & - & - & - & NA & 38 & NED \\
\hline \#15 & $M$ & 76 & $\mathrm{~N}-\mathrm{E}$ & $\mathrm{E}$ & - & CER & $\mathrm{T}_{4 \mathrm{a}} \mathrm{N}_{0} \mathrm{M}_{0}$ & - & $\mathrm{T}, \mathrm{M}^{\top}$ & 5 & CHT & 10 & DOD \\
\hline$\# 16$ & $M$ & 59 & $\mathrm{~N}-\mathrm{E}$ & $\mathrm{E}$ & $\mathrm{CHT}$ & CER & $\mathrm{T}_{4 \mathrm{~b}} \mathrm{~N}_{2 \mathrm{~b}} \mathrm{M}_{0}$ & - & $\mathrm{T}, \mathrm{M}^{\mathrm{L}}$ & 9 & $S$ & 11 & DOD \\
\hline$\# 17$ & $\mathrm{~F}$ & 64 & $\mathrm{~N}-\mathrm{E}$ & $\mathrm{E}$ & $\mathrm{S}, \mathrm{CHT}$ & CER & $\mathrm{T}_{4 \mathrm{~b}} \mathrm{~N}_{0} \mathrm{M}_{0}$ & RT & $\mathrm{T}, \mathrm{M}^{\mathrm{L}, \mathrm{AG}}$ & 1 & $\mathrm{CHT}$ & 11 & DOD \\
\hline \#18 & $\mathrm{F}$ & 73 & $\mathrm{~N}-\mathrm{E}$ & $\mathrm{E}$ & - & ERTC & $\mathrm{T}_{4 \mathrm{a}} \mathrm{N}_{0} \mathrm{M}_{0}$ & - & - & - & NA & 21 & NED \\
\hline \#19 & $M$ & 79 & $\mathrm{~N}-\mathrm{E}$ & $\mathrm{E}$ & - & ERTC & $\mathrm{T}_{4 \mathrm{~b}} \mathrm{~N}_{0} \mathrm{M}_{0}$ & - & $\mathrm{T}, \mathrm{M}^{\mathrm{L}}$ & 4 & - & 7 & DOD \\
\hline \#20 & $\mathrm{F}$ & 49 & $\mathrm{~N}-\mathrm{E}$ & $\mathrm{E}, \mathrm{S}$ & - & ERTC & $\mathrm{T}_{4 \mathrm{~b}} \mathrm{~N}_{0} \mathrm{M}_{0}$ & CHT & $\mathrm{T}, \mathrm{M}^{\mathrm{L}}$ & 1 & CHT & 17 & AWD \\
\hline \#21 & $M$ & 85 & $M$ & $\mathrm{E}$ & - & ERTC & $\mathrm{T}_{4 \mathrm{a}} \mathrm{N}_{0} \mathrm{M}_{0}$ & - & $\mathrm{T}$ & 8 & $S$ & 8 & DOD \\
\hline \#22 & $\mathrm{F}$ & 71 & $N-E$ & $\mathrm{E}$ & - & ERTC & $\mathrm{T}_{4 \mathrm{~b}} \mathrm{~N}_{0} \mathrm{M}_{0}$ & - & $\mathrm{T}$ & 1 & - & 3 & DOD \\
\hline \#23 & $M$ & 35 & $\mathrm{~N}-\mathrm{E}$ & E, S & $\mathrm{S}$ & CER & $\mathrm{T}_{4 \mathrm{a}} \mathrm{N}_{0} \mathrm{M}_{0}$ & CHT,RT & $\mathrm{M}^{\mathrm{L}, \mathrm{B}, \mathrm{BO}}$ & 12 & - & 16 & DOD \\
\hline \#24 & $\mathrm{F}$ & 79 & $\mathrm{~N}-\mathrm{E}$ & $\mathrm{E}$ & $\mathrm{S}$ & ERTC & $\mathrm{T}_{3} \mathrm{~N}_{0} \mathrm{M}_{0}$ & - & $\mathrm{M}^{\mathrm{L}, \mathrm{P}, \mathrm{PA}, \mathrm{K}, \mathrm{BO}}$ & 1 & CHT & 33 & AWD \\
\hline \#25 & $\mathrm{M}$ & 53 & $M$ & $\mathrm{E}$ & - & CHT & $\mathrm{T}_{4 \mathrm{~b}} \mathrm{~N}_{0} \mathrm{M}_{1}$ & NA & $\mathrm{M}^{\mathrm{L}, \mathrm{P}, \mathrm{BO}}$ & 10 & CHT & 29 & DOD \\
\hline \#26 & $\mathrm{M}$ & 78 & $\mathrm{~N}-\mathrm{E}$ & $\mathrm{E}$ & - & ERTC & $\mathrm{T}_{3} \mathrm{~N}_{0} \mathrm{M}_{0}$ & - & $\mathrm{T}, \mathrm{M}^{\mathrm{B}, \mathrm{L}}$ & 3 & - & 10 & DOD \\
\hline \#27 & $\mathrm{M}$ & 54 & $M$ & S & - & ERTC & $\mathrm{T}_{4 \mathrm{a}} \mathrm{N}_{0} \mathrm{M}_{0}$ & - & $\mathrm{M}^{\mathrm{L}}$ & 1 & CHT & 7 & DOD \\
\hline \#28 & $\mathrm{M}$ & 84 & $\mathrm{M}$ & E & - & ERTC & $\mathrm{T}_{3} \mathrm{~N}_{0} \mathrm{M}_{0}$ & - & $\mathrm{T}, \mathrm{M}^{\mathrm{L}, \mathrm{LI}}$ & 5 & $\mathrm{~S}$ & 22 & DOD \\
\hline \#29 & $\mathrm{M}$ & 81 & $\mathrm{~N}-\mathrm{E}$ & $\mathrm{E}$ & - & ERTC & $\mathrm{T}_{3} \mathrm{~N}_{1} \mathrm{M}_{0}$ & - & $\mathrm{T}, \mathrm{M}^{\mathrm{B}, \mathrm{L}}$ & 5 & $\mathrm{~S}$ & 34 & DOD \\
\hline \#30 & $\mathrm{M}$ & 76 & $\mathrm{~N}-\mathrm{E}$ & $\mathrm{E}$ & - & ERTC & $\mathrm{T}_{3} \mathrm{~N}_{0} \mathrm{M}_{0}$ & - & $\mathrm{T}, \mathrm{N}, \mathrm{M}^{\mathrm{L}}$ & 6 & $\mathrm{~S}$ & 21 & DOD \\
\hline \#31 & $\mathrm{F}$ & 70 & $M$ & $\mathrm{E}$ & - & $\mathrm{CHT}$ & $\mathrm{T}_{3} \mathrm{~N}_{0} \mathrm{M}_{1}$ & NA & $\mathrm{M}^{\mathrm{L}, \mathrm{P}, \mathrm{PA}, \mathrm{K}, \mathrm{BO}}$ & 1 & $\mathrm{CHT}$ & 20 & DOD \\
\hline \#32 & $M$ & 51 & $\mathrm{~N}-\mathrm{E}$ & $\mathrm{E}$ & - & ERTC & $\mathrm{T}_{4 \mathrm{a}} \mathrm{N}_{0} \mathrm{M}_{0}$ & - & - & - & $N A$ & 19 & NED \\
\hline
\end{tabular}

Abbreviations: M, maxillary sinus; E, epithelioid morphology; CFR, cranio-facial resection; DOD, dead of disease; N-E, naso-ethmoidal complex; RT, radiotherapy; NA, not applicable; NED, no evidence of disease; CHT, chemotherapy; ERTC, endoscopic resection with trans-nasal craniectomy; T, trachea; S, spindle cells morphology; AWD, alive with disease; CER, cranio-endoscopic resection; S, surgery; P, pleura; B, brain; L, lung; SK, skin; LI, liver; G, gut; AG, adrenal glands; BO, bone; PA, pancreas; K, kidney.

extracted using the QIAamp DNA FFPE Tissue kit (Qiagen). Direct sequencing of KIT (exons 9, 11, 13, 17, 18), NRAS (exons 2 and 3), BRAF (exon 15), and PI3KCA (exons 9 and 20) was performed using the Big Dye Terminator v3.1 Cycle Sequencing kit (Applied Biosystems, Foster City, CA) in accord with the manufacturer's instructions for the 3130 Genetic Analyzer. The primers used for mutational analysis were as follows: BRAF exon 15F 5'-TGCTTGCTCTGATAGGAAAATG-3'; BRAF exon 15R 5'-AGCATCTCAGGGCCAAAAAT-3'; KIT exon 9F 5'-AGCCAGGGCTTTTGTTTTCT-3'; KIT exon 9R 5'-TGGTAGACAGAGCCTAAACATCC-3'; KIT exon $11 \mathrm{~F} \quad 5^{\prime}$-CCAGAGTGCTCTAATGACTG-3'; KIT exon 11R 5'-ACCCAAAAAGGTGACATGGA-3'; KIT exon 13F $5^{\prime}$-CGGCCATGACTGTCGCTGTAA-3'; KIT exon 13R 5'-CTCCAATGGTGCAGGCTCCAA-3'; KIT exon $17 \mathrm{~F} 5^{\prime}$-ATGGTTTTCTTTTCTCCTCC-3'; KIT exon 17R 5'-CAGGACTGTCAAGCAGAGAAT-3'; KIT exon 18F 5'-CATTTCAGCAACAGCAGCAT-3'; KIT exon 18R 5'-CAAGGAAGCAGGACACCAAT-3'; NRAS exon 2F 5'-CAACAGGTTCTTGCTGGTGT-3'; NRAS exon 2R 5'-CCTCACCTCTATGGTGGGAT-3'; NRAS exon 3F 5'-GATTCTTACAGAAAACAAGTG-3'; NRAS exon 3R $\quad 5^{\prime}$-ATGACTTGCTATTATTGATGG-3'; PI3KCA exon 9F 5'-GCTTTTTCTGTAAATCATCTGTG - $3^{\prime}$; PI3KCA exon 9R 5'-CTGAGATCAGCCAAATTCAGT3'; PI3KCA exon 20F 5'-CATTTGCTCCAAACTGACCA-3'; PI3KCA exon 20R 5'-CAATTCCTATGCAATCGGTCT- $3^{\prime}$. Mutations were confirmed with a second DNA extraction on a different level of the tissue block.

\section{Statistical analysis}

SPSS v 10.0.1, 1999 (SPSS, Chicago, IL) was adopted and survival estimates were calculated by the Kaplan-Meier method. Univariate comparisons between groups were performed using the log-rank test. Any $p$ values $<.05$ were considered statistically significant.

\section{RESULTS}

\section{Primary sinonasal mucosal melanomas are aggressive melanomas with high propensity to distant spreading}

The main clinical and pathological findings of the patients are summarized in Table 1. Patients (17 men and 15 women) ranged in age from 35 to 88 years (mean, 69.5 years). All tumors originated in the sinonasal tract: 
TABLE 2. Mutational analysis of primary sinonasal mucosal melanomas.

\begin{tabular}{lrllr}
\hline Gene & Exon & cDNA & Protein & Case \\
\hline KIT & 11 & $1671 \mathrm{G}>\mathrm{C}$ & W557C & $\# 5$ \\
& 11 & $1727 \mathrm{C}>\mathrm{C}$ & L576P & $\# 15$ \\
& 11 & $1672 \mathrm{~A}>\mathrm{G}$ & K558E & $\# 25$ \\
\multirow{4}{*}{ NRAS } & 18 & $2591 \mathrm{C}>\mathrm{T}$ & S864F & $\# 11$ \\
& 2 & $37 \mathrm{G}>\mathrm{T}$ & $\mathrm{G} 13 \mathrm{C}$ & $\# 20$ \\
& 2 & $38 \mathrm{G}>\mathrm{A}$ & $\mathrm{G} 13 \mathrm{D}$ & $\# 21$ \\
& 2 & $35 \mathrm{G}>\mathrm{A}$ & $\mathrm{G} 12 \mathrm{D}$ & $\# 30$ \\
& 2 & $35 \mathrm{G}>\mathrm{C}$ & $\mathrm{G} 12 \mathrm{~A}$ & $\# 32$ \\
& 3 & $182 \mathrm{~A}>\mathrm{T}$ & $\mathrm{Q} 61 \mathrm{~L}$ & $\# 10$ \\
& 3 & $182 \mathrm{~A}>\mathrm{G}$ & $\mathrm{Q} 61 \mathrm{R}$ & $\# 13$ \\
BRAF & 3 & $182 \mathrm{~A}>\mathrm{G}$ & $\mathrm{Q} 61 \mathrm{R}$ & $\# 24$ \\
& 15 & $1781 \mathrm{~A}>\mathrm{G}$ & $\mathrm{D} 594 \mathrm{G}$ & $\# 7$ \\
\hline
\end{tabular}

$23(71.9 \%)$ in the naso-ethmoidal complex and the remaining $9(28.1 \%)$ in the maxillary sinus. In accord with the 2010 Union Internationale Contre le Cancer Staging System, primary lesions were classified as follows: 17 cases $(53.1 \%)$ pT3; 8 (25\%) pT4a; and 7 (21.9\%) pT4b. Twenty-nine patients $(90.6 \%)$ underwent surgery tailored to the extension of disease (Table 1). Neck dissection was performed only in 3 patients and planned according to the nodal metastasis features (localization, size, number, and possible extracapsular extension). Three patients $(9.4 \%)$ with maxillary melanoma were not considered amenable for surgical excision due to the presence of distant metastases at diagnosis and were treated with palliative chemotherapy.

Follow-up ranged between 3 and 94 months (mean, 24.6 months) and was available in all cases. The three patients treated with palliative chemotherapy developed uncontrolled spreading of their disease and died of disease in a short period (mean, 20.6 months). Among the 29 surgically treated patients, $24(82.7 \%)$ experienced 1 or more recurrences. In 17 of 29 patients (58.6\%), a local relapse was identified, whereas regional and distant failure occurred in 4 of $29(13.8 \%)$ and 20 of $29(68.9 \%)$ cases, respectively. Sites of distant failure were broadly distributed: lung in 18 of 32 cases $(56.2 \%)$; brain in 7 of $32(21.9 \%)$; bone in 4 of $32(12.5 \%)$; pleura in 3 of 32 (9.4\%); adrenal glands, liver, kidney, and pancreas in 2 of 32 cases $(6.2 \%)$ each; and skin, trachea, and gut in 1 case each $(3.1 \%)$.

At the last follow-up, performed in December 2011, 24 of 32 patients $(75 \%)$ had died of disease in a period ranging from 3 to 59 months (mean survival, 18 months), mainly for metastatic spread of disease. The remaining 8 patients were alive, 3 of $32(9.4 \%)$ with disease and 5 of $32(15.6 \%)$ free of disease. The 5-year overall survival of the patient cohort was $25.8 \pm 14.9 \%$. These data confirm the highly aggressive behavior of this neoplasm ${ }^{15}$ with an urgent need of alternative strategies for treatment. ${ }^{16}$

\section{Primary sinonasal mucosal melanomas is characterized by occurrence NRAS and KIT mutations, and the lack of BRAF V600E}

By direct sequencing, we analyzed our cohort of primary sinonasal mucosal melanomas for BRAF, NRAS, and KIT mutations in "hot-spot" coding exons (Table 2 and Figure 1). The majority of cases lacked BRAF mutations in exon $15(31 / 32 ; 97 \%)$; 1 case (case 7$)$ harbored a D594G mutation. The classic BRAF V600E mutation was not found in any cases. Conversely, NRAS mutations where found in 7 of 32 cases $(22 \%)$. Of these, $3(42.8 \%)$ involved codon 61 (cases 10, 13, and 24), whereas the remaining 4 were found on codons 12 (28.5\%; cases 30 and 32) and 13 (28.5\%; cases 20 and 21). We screened all primary sinonasal mucosal melanomas for KIT mutations in exons 9, 11, 13, 17, and 18. In 4 of 32 cases $(12.5 \%)$, we found KIT mutations in exon 11 (cases 5, 15, and 25) and exon 18 (case 11).

By immunohistochemistry, KIT protein expression (score 1-4) was found in 31 of 32 cases $(96.9 \%$; Table 3 and Figure 2). The majority of cases (19 of 32; $59.4 \%$ ) showed diffuse and intense (score 3 and 4) KIT reactivity. Where present, the intraepithelial component of the tumor was also positive ( 8 of 10 cases; $80 \%$ ). By analyzing the subcellular localization of the KIT protein, we found that 12 of 32 cases $(37.5 \%)$ showed diffuse cytoplasmic and membrane staining, whereas in 18 of 32 cases $(56.2 \%)$ KIT expression was limited to the cytoplasm of tumor cells; in 1 of 32 cases (3.1\%) staining was confined to the tumor cell membrane. Among the 4 primary sinonasal mucosal melanomas with somatic mutations of the KIT gene, 3 cases (cases 5, 15, and 11) showed strong and diffuse protein expression, whereas in 1 case (case 25 ) reactivity was weak, cytoplasmic, and limited to a minor portion of the tumor.

\section{Primary sinonasal mucosal melanomas shows amplification of RREB1 and loss of $M Y B$, but lack CCND1 amplification}

A recently published probe combination for $R R E B 1 /$ LSI, MYB/LSI, and CCNDI/CEP6 can be used to detect chromosomal and gene aberrations commonly found in cutaneous melanomas. ${ }^{14}$ These abnormalities are represented by increased copy number of CCND1 (11q13) and RREB1 (6p25) followed by $6 \mathrm{q} 23$ loss relative to CEP6. A commercially available 4-color FISH assay has demonstrated high sensitivity and specificity in detecting these abnormalities in cutaneous melanomas. ${ }^{17}$ Seventeen of the primary sinonasal mucosal melanomas cases in our cohort were suitable for FISH analysis (Table 4 and Figure $3 \mathrm{~A}$ and $3 \mathrm{~B}$ ). The overall sensitivity of the assay was $100 \%$ (with at least 1 alteration detected). In particular, all cases showed gain of $6 \mathrm{p} 25$ (RREB1; all of $17 ; 100 \%$ ), whereas loss of $6 \mathrm{q} 23$ $(M Y B)$ was present in $76 \%$ of cases (13 of 17). Gain of CCND1 (11q13) was observed in 1 case (1 of $17 ; 5.8 \%$; case 22) only with Gerami criteria ${ }^{14}$ (Table 4). These data suggest that chromosomal and genetic abnormalities detected in cutaneous melanomas by the melanoma FISH approach can also be observed in primary sinonasal mucosal melanomas. Interestingly, a very similar profile (high rate of $6 \mathrm{p} 25$ gain and $6 \mathrm{q} 23$ loss) is found in the acro-lentiginous (AL) subgroup. ${ }^{7}$ However, compared to the AL subgroup, the primary sinonasal mucosal melanomas lacked CCNDI gene amplification, as confirmed on 6 over-expressing cases (cases 2, 3, 9, 14, 


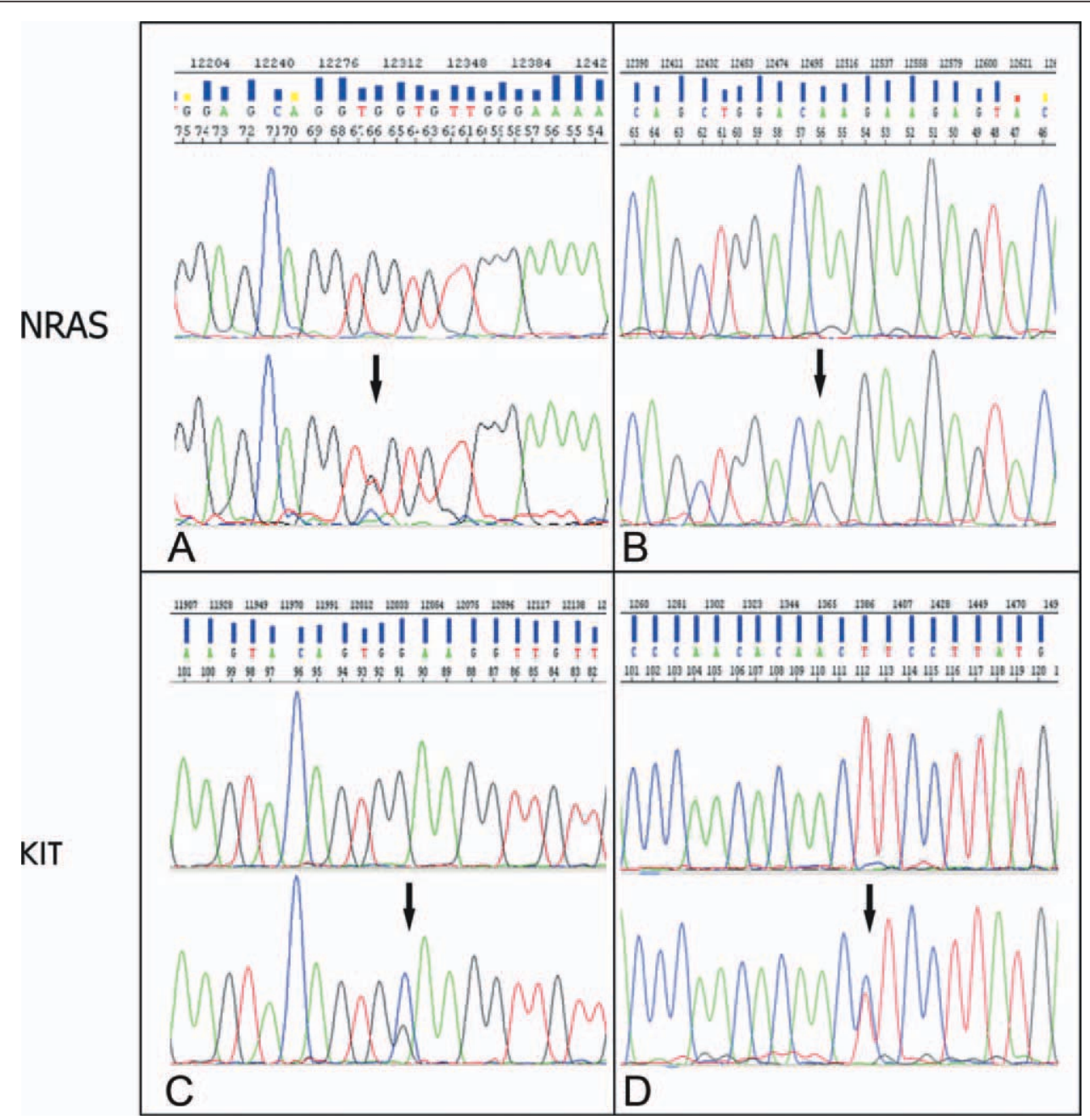

FIGURE 1. Somatic mutation of NRAS (A and B) and KIT (C and D) in primary sinonasal mucosal melanomas. Black arrows indicate NRAS mutations affecting exon 2 (G13C, case 20 in A) and 3 (Q61R, case 13 in B) and KIT mutations in exon 11 (W557C, case 5 in C; L576P, case 15 in D). A corresponding wild-type sequence is shown in each of the 4 panels. [Color figure can be viewed in the online issue, which is available at wileyonlinelibrary.com.]

16, and 22) by using an alternative FISH assay with a centromeric probe for chromosome 11. However, a large proportion of cases $(65.6 \%$, score $>1)$, including those tested with the melanoma FISH, showed overexpression of Cyclin D1 by immunohistochemistry (Table 3 and Figure 3C and 3D).
Loss of tumor suppressor genes PTEN and $p 16$ in primary sinonasal mucosal melanomas

Loss of tumor suppressor genes expression involving PTEN and INK4a has been variably detected in sporadic cutaneous melanoma. ${ }^{2,18}$ Using immunohistochemistry, we examined the expression of PTEN and p16/INK4a in

TABLE 3. Summary of immunohistochemical staining of primary sinonasal mucosal melanomas.

\begin{tabular}{llllrr}
\hline & \multicolumn{5}{c}{ Score } \\
\cline { 2 - 5 } Marker & $\mathbf{0}$ & 1 & 2 & \multicolumn{1}{c}{3} \\
\hline KIT & $1 / 32(3.1 \%)$ & $5 / 32(15.6 \%)$ & $7 / 32(21.9 \%)$ & $7 / 32(21.9 \%)$ & $12 / 32(37.5 \%)$ \\
CCND1 & $5 / 32(15.6 \%)$ & $6 / 32(18.8 \%)$ & $5 / 32(15.6 \%)$ & $11 / 32(34.4 \%)$ & $5 / 32(15.6 \%)$ \\
PTEN & $9 / 27(33.3 \%)$ & $2 / 27(7.4 \%)$ & $2 / 27(7.4 \%)$ & $8 / 27(29.6 \%)$ & $6 / 27(22.2 \%)$ \\
p-16 & $2 / 29(6.9 \%)$ & $6 / 29(20.7 \%)$ & $8 / 29(27.6 \%)$ & $0 / 29(0 \%)$ & $13 / 29(44.8 \%)$ \\
pERK & $0 / 27(0 \%)$ & $3 / 27(11.1 \%)$ & $3 / 27(11.1 \%)$ & $18 / 27(66.7 \%)$ & $3 / 27(11.1 \%)$ \\
pAkt & $0 / 29(0 \%)$ & $3 / 29(10.3 \%)$ & $0 / 29(0 \%)$ & $5 / 29(17.3 \%)$ & $21 / 29(72.4 \%)$ \\
\hline
\end{tabular}

Notes: Score $0=$ absence of positive cells; score $1=1 \%$ to $25 \%$ of positive cells; score $2=25 \%$ to $50 \%$ of positive cells; score $3=50 \%$ to $75 \%$ of positive cells; score $4=>75 \%$ of positive cells. 


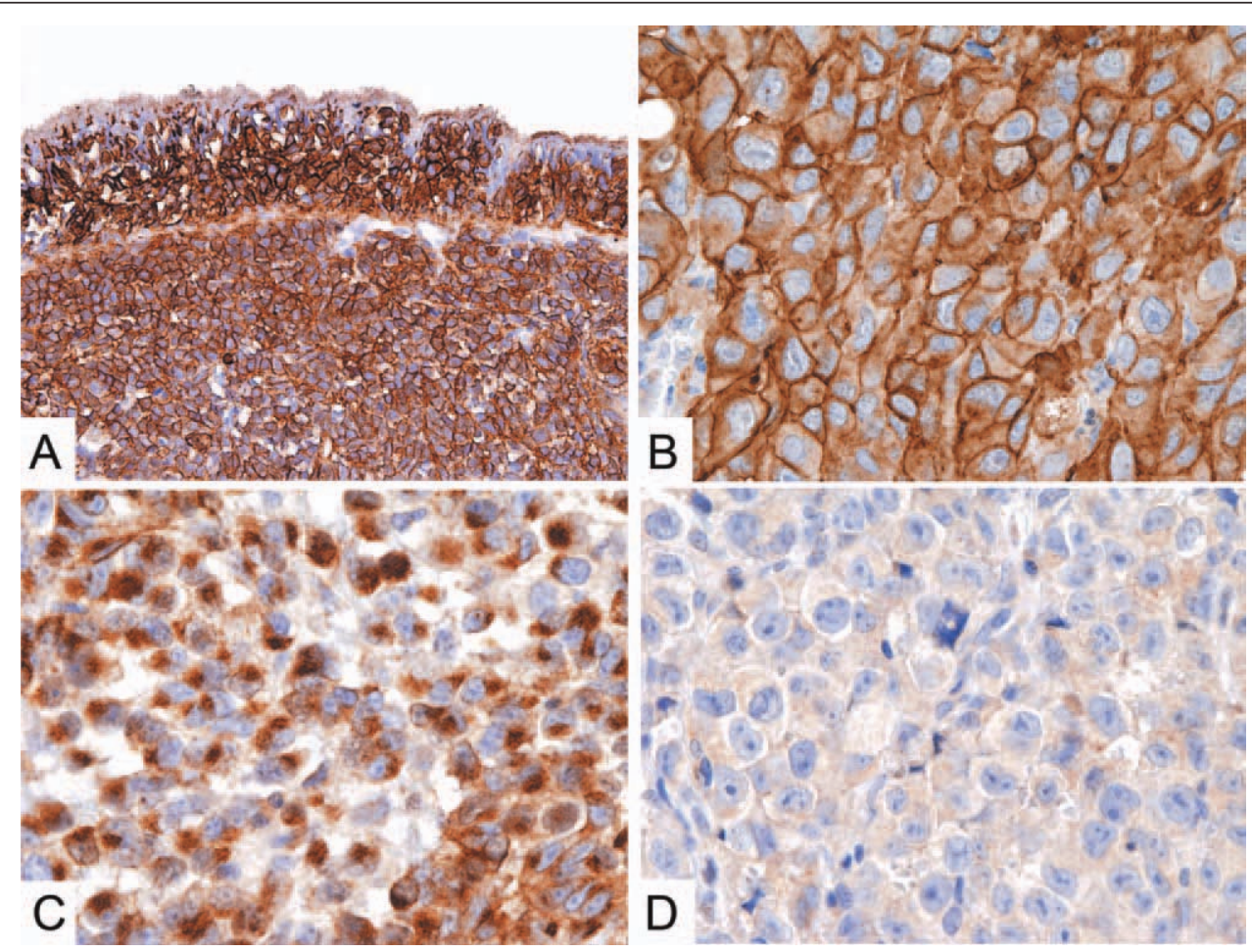

FIGURE 2. Expression of KIT (CD117) in primary sinonasal mucosal melanomas. CD117 expression is found in intraepithelial and infiltrating primary sinonasal mucosal melanomas cells (A). The staining pattern of CD117 ranges from a strong membrane (A and B) or cytoplasmic (C) signal to weak or absent expression (D). For immunohistochemistry, sections were counterstained with Meyer's hematoxylin and secondary antibodies revealed with DAB (brown). Original magnification $\times 100(A)$ and $\times 600(B-D)$. [Color figure can be viewed in the online issue, which is available at wileyonlinelibrary.com.]

our cohort of primary sinonasal mucosal melanomas. The expression was variable from case to case, and showed tumor heterogeneity even within individual tumors (Table 3 and Figure 4A-4D). In particular, loss of PTEN expression $(<50 \%$ of positive cells; score $0-2)$ was observed in
13 of 27 cases $(48.1 \%)$ with a total absence of the protein (score 0) in 9 of 27 cases $(33.3 \%)$. CDKN2A generates at least 3 structurally and functionally unrelated transcriptional variants that include p16/INK4a, p14ARF, and p12. Loss of p16 protein in primary sinonasal mucosal

TABLE 4. Details on melanoma fluorescence in situ hybridization following Abbott and Gerami criteria.

\begin{tabular}{|c|c|c|c|c|c|c|c|c|}
\hline \multirow[b]{2}{*}{ Case } & \multicolumn{4}{|c|}{ Abbott/Germany } & \multicolumn{4}{|c|}{ Gerami et al., 2009} \\
\hline & $\begin{array}{l}\text { Nuclei abnormal } \\
\text { for } R R E B 1(6 \mathrm{p} 25) \\
\text { signals: } \geq 63 \%\end{array}$ & $\begin{array}{c}\text { Average } M Y B \\
\text { (6q23) signals for } \\
\text { nucleus: } \geq 2.5 \%\end{array}$ & $\begin{array}{c}\text { Loss in } M Y B \\
(6 q 23) \text { relative } \\
\text { to } C E P 6: \geq 31 \%\end{array}$ & $\begin{array}{c}\text { Average CCND1 } \\
\text { (11q13) signals for } \\
\text { nucleus: } \geq 2.5 \%\end{array}$ & $\begin{array}{l}\text { Gain in RREB1 } \\
\text { (6p25): }>29 \%\end{array}$ & $\begin{array}{l}\text { Gain in } R R E B 1 \\
\text { (6p25) relative } \\
\text { to CEP6: }>55 \%\end{array}$ & $\begin{array}{c}\text { Loss in } M Y B \\
(6 q 23) \text { relative } \\
\text { to } C E P 6:>40 \%\end{array}$ & $\begin{array}{c}\text { Gain in } \\
\text { CCND1 } \\
\text { (11q13): }>38 \%\end{array}$ \\
\hline \#2 & $100 \%$ & $2.16 \%$ & $76.60 \%$ & $2.23 \%$ & $100 \%$ & $66.30 \%$ & $76.60 \%$ & $33.30 \%$ \\
\hline \#3 & $96.60 \%$ & $1.63 \%$ & $16.60 \%$ & $1.70 \%$ & $96.60 \%$ & $100 \%$ & $16.60 \%$ & $10 \%$ \\
\hline$\# 7$ & $100 \%$ & $1.36 \%$ & $90 \%$ & $1.30 \%$ & $100 \%$ & $66.60 \%$ & $90 \%$ & $0 \%$ \\
\hline$\# 9$ & $80 \%$ & $1.56 \%$ & $50 \%$ & $2.23 \%$ & $80 \%$ & $63.30 \%$ & $50 \%$ & $33.30 \%$ \\
\hline \#12 & $100 \%$ & $2.13 \%$ & $43.30 \%$ & $1.66 \%$ & $100 \%$ & $76.60 \%$ & $43.30 \%$ & $13.30 \%$ \\
\hline$\# 14$ & $56.60 \%$ & $2.30 \%$ & $10 \%$ & $2.06 \%$ & $56.60 \%$ & $50 \%$ & $10 \%$ & $13.30 \%$ \\
\hline \#15 & $100 \%$ & $1.56 \%$ & $70 \%$ & $2.20 \%$ & $100 \%$ & $50 \%$ & $70 \%$ & $36.60 \%$ \\
\hline \#16 & $100 \%$ & $2 \%$ & $86.60 \%$ & $1.93 \%$ & $100 \%$ & $43.30 \%$ & $86.60 \%$ & $23.30 \%$ \\
\hline \#19 & $100 \%$ & $1.36 \%$ & $40 \%$ & $1.23 \%$ & $100 \%$ & $83.30 \%$ & $40 \%$ & $0 \%$ \\
\hline \#22 & $96.60 \%$ & $2.60 \%$ & $13.30 \%$ & $2.10 \%$ & $96.60 \%$ & $80 \%$ & $13.30 \%$ & $40 \%$ \\
\hline \#24 & $100 \%$ & $2.00 \%$ & $70 \%$ & $1.80 \%$ & $100 \%$ & $86.60 \%$ & $70 \%$ & $3.33 \%$ \\
\hline \#25 & $100 \%$ & $2.20 \%$ & $36.60 \%$ & $1.50 \%$ & $100 \%$ & $86.60 \%$ & $36.60 \%$ & $3.33 \%$ \\
\hline \#26 & $96.60 \%$ & $1.06 \%$ & $26.60 \%$ & $1.36 \%$ & $96.60 \%$ & $100 \%$ & $26.60 \%$ & $3.33 \%$ \\
\hline \#27 & $96.60 \%$ & $1,23 \%$ & $70 \%$ & $1,6 \%$ & $96.60 \%$ & $76.60 \%$ & $70 \%$ & $0 \%$ \\
\hline \#30 & $100 \%$ & $1.16 \%$ & $50 \%$ & $1.13 \%$ & $100 \%$ & $100 \%$ & $50 \%$ & $0 \%$ \\
\hline \#31 & $100 \%$ & $1.16 \%$ & $63.30 \%$ & $1.63 \%$ & $100 \%$ & $76.60 \%$ & $63.30 \%$ & $3.33 \%$ \\
\hline \#32 & $96.60 \%$ & $1.83 \%$ & $50 \%$ & $1.36 \%$ & $96.60 \%$ & $76.60 \%$ & $50 \%$ & $0 \%$ \\
\hline
\end{tabular}

Note: Values over the cut-off are in bold face. 


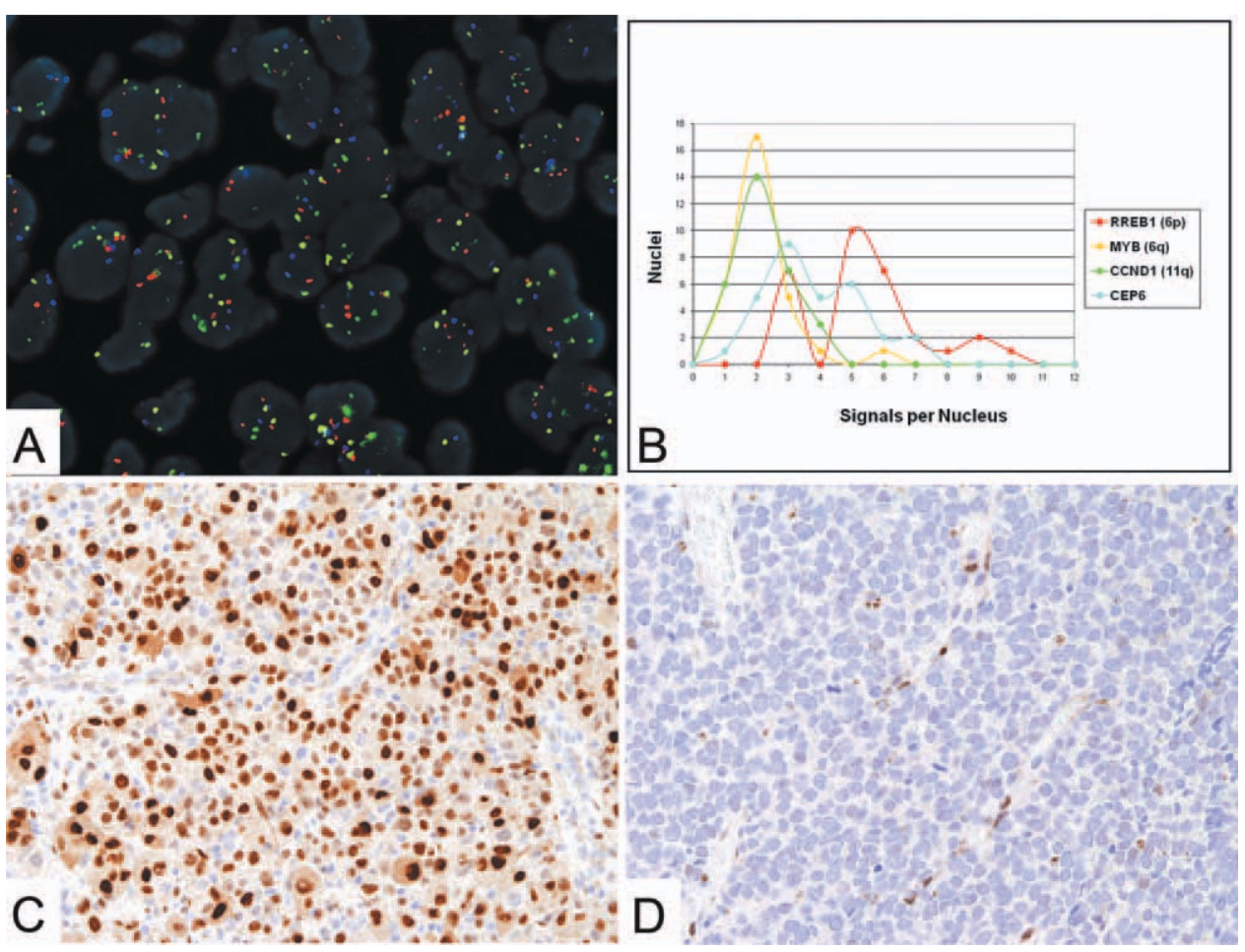

FIGURE 3. Melanoma fluorescence in situ hybridization (FISH) and CCDN1 expression in primary sinonasal mucosal melanomas. A FISH image (A) with the corresponding box plot (B) of a prototypical primary sinonasal mucosal melanomas case (case 2) showing gain of RREB1, loss of $M Y B$ relative to CEP6 and normal CCND1. Two examples of primary sinonasal mucosal melanomas showing diffuse (score 4) and absent (score 0) CCND1 expression are shown in (C) and (D), respectively. For immunohistochemistry, sections were counterstained with Meyer's hematoxylin and secondary antibodies revealed with DAB (brown). Original magnification $\times 600(A)$ and $\times 400 x(B-D)$. [Color figure can be viewed in the online issue, which is available at wileyonlinelibrary.com.]

melanomas is associated with 9 p21 deletion by FISH. ${ }^{19}$ In our cohort of primary sinonasal mucosal melanomas, loss of p16/INK4a in more than $50 \%$ of tumor cells (score 0-2) was observed in 16 of 29 cases $(55.2 \%)$; however, among these, only 2 showed complete loss (score 0 ) of the protein. We performed FISH analysis on the 9 p21 region. Fifteen cases were suitable for signal interpretation. Of these, only 3 tumors (cases 20, 26, and 30) showed heterozygous deletion of $9 \mathrm{p} 21$ including the 2 cases completely lacking p16 protein (insert in Figure 4B). By combining these data, we found that although heterogeneously, lack of at least 1 tumor-suppressor gene (score $\leq 2)$ was present in the large majority of cases (24 of $29 ; 82.7 \%$ ), whereas combined loss of p16 and PTEN ( 5 of $27 ; 18.5 \%$ ) represented a more rare event. In addition, complete loss (score 0) of a tumor-suppressor gene was a mutually exclusive event, because only 1 of 27 cases $(3.7 \%)$ showed combined complete loss of both PTEN and p16 (case 28).

\section{Activation of PI3K-Akt and RAS-MAPK pathways is a common event in primary sinonasal mucosal melanomas}

Among relevant pathways sustaining melanoma cell survival, proliferation, and invasion, activation of PI3KAkt and RAS-MAPK are the best characterized. ${ }^{2,18}$ The availability of antibodies recognizing the phosphorylated forms Akt and ERK on fixed tissues allows direct testing of the activation of PI3K-Akt and RAS-MAPK pathways on tumor cells. Our cohort of primary sinonasal mucosal melanomas was analyzed for the expression of pAkt and pERK by immunohistochemistry (Table 3 and Figure 4E and 4F). Interestingly, all cases (all of 29) were positive for pAkt expression and, when scored based on the percentage of positive tumor cells, the level of heterogeneity for this marker was very low. In particular, strong and diffuse pAkt expression (score 3 and 4) was very common (26 of $29 ; 89.7 \%$ ), whereas in 3 of 29 cases $(10.3 \%$, score 1) positive pAkt staining was seen in less than $25 \%$ of tumor cells (score $=1)$. The pAkt activation in cancer might depend on PTEN loss or activating mutations of PI3KCA which encode for the main catalytic subunit of the phosphatidylinositol 3-kinases. By analyzing 9 cases of primary sinonasal mucosal melanomas (cases 1, 3, 6, $8,9,12,14,16,19)$, including 3 cases with preserved PTEN expression, no mutations in the exons 9 and 20 of PIK3CA were found. Similar to pAkt, all cases (all of 27) stained for pERK. The staining pattern was strong and diffuse (score 3 and 4 ) in a large proportion of cases (21 of $27 ; 77.8 \%$ ), whereas in the remaining cases (6 of 27 , 22.2) less than $50 \%$ of tumor cells were positive (score 1 and 2).

Taken together, these data indicate that the PI3K-Akt and RAS-MAPK pathways are commonly activated in primary sinonasal mucosal melanomas. In particular, this 


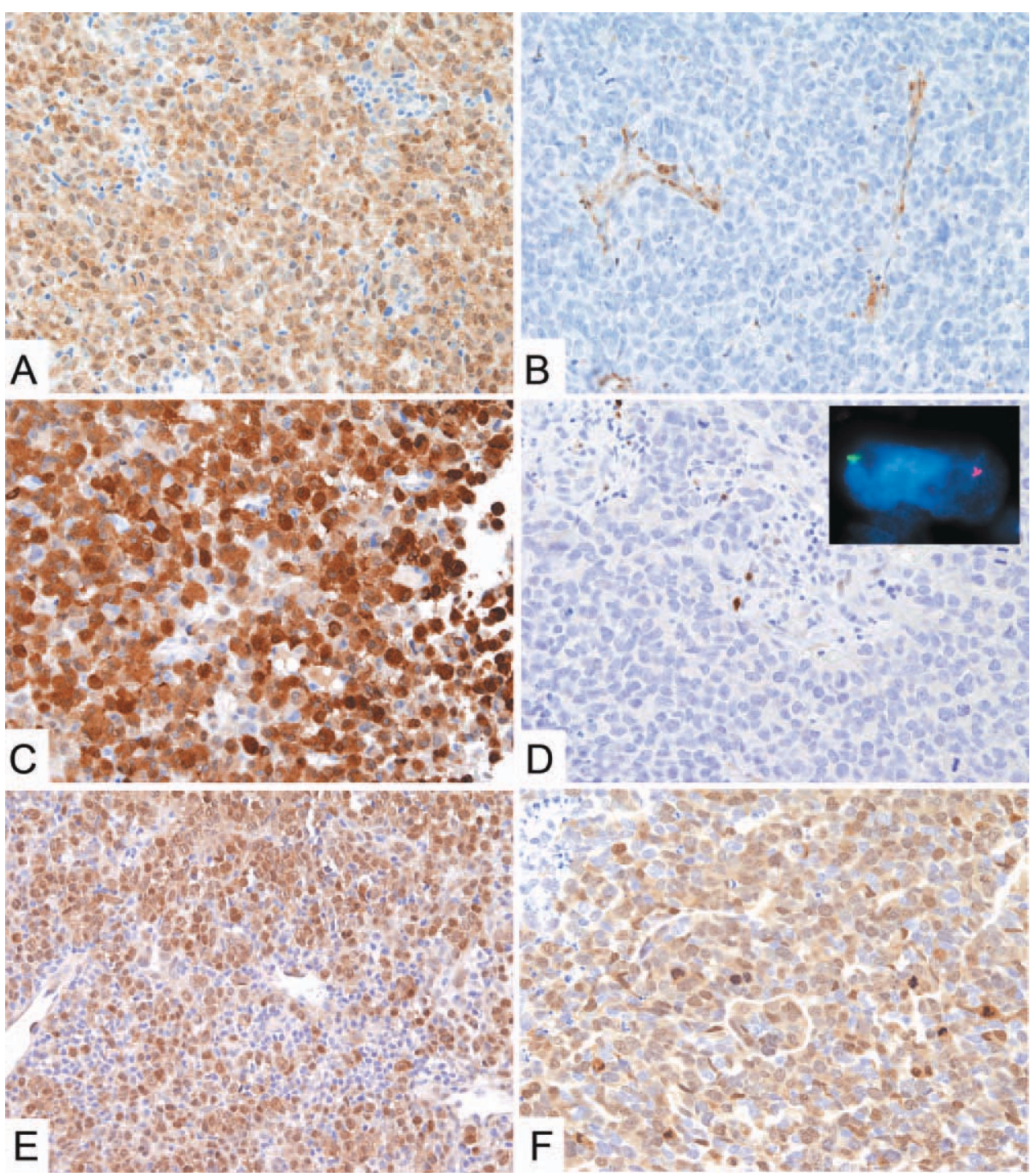

FIGURE 4. Expression of p16, PTEN, pERK, and pAkt in primary sinonasal mucosal melanomas. Representative primary sinonasal mucosal melanomas cases showing expression of PTEN (score 4 in A and score 0 in B), p16 (score 4 in C and score 0 in D), pERK (score 4 in E), and pAkt (score 4 in F). Lack of a signal for p16 in case 20 is associated with 9p21 deletion by fluorescence in situ hybridization (FISH; insert in D). For immunohistochemistry, sections were counterstained with Meyer's hematoxylin and secondary antibodies revealed with DAB (brown). Original magnification $\times 400(\mathrm{~A}-\mathrm{F})$ and $\times 600$ (insert in B). [Color figure can be viewed in the online issue, which is available at wileyonlinelibrary.com.]

occurs either in cases with constitutive activation of the pathway due to mutation in known oncogenes (KIT, NRAS, and BRAF), but also in other cases where the pathway inducer is still unknown.

\section{Clinical correlations}

To verify the prognostic significance of the major molecular abnormalities detected in primary sinonasal mucosal melanomas, we performed a survival analysis of different primary sinonasal mucosal melanoma subgroups. In terms of 5-year overall survival, no significant differences were observed with regard to occurrence of NRAS mutations $(33.3 \pm 25.5 \%$ vs $30.7 \pm 17.3 \% ; p=.32)$, KIT mutations $(25 \pm 21.7 \%$ vs $31.6 \pm 17.1 \% ; p=.51)$, loss of PTEN in $>50 \%$ of tumor cells $(37.5 \pm 28.6 \%$ vs $18.6 \pm 15.9 \% ; p=.09)$, and loss of p16/INK $4 \mathrm{a}$ in $>50 \%$ of tumor cells $(21.8 \pm 18.5 \%$ vs $27.5 \pm 22.8 \% ; p=$ $.71)$.

\section{DISCUSSION}

In this study, we report a detailed clinical and molecular analysis of a homogenous cohort of 32 cases of primary sinonasal mucosal melanomas. Our series confirms previous studies ${ }^{15}$ indicating that primary sinonasal mucosal melanomas is an aggressive melanocytic neoplasm characterized by a high tendency to recur and to metastasize at various distant sites. This behavior depends on the significant delay in diagnosis and on the intrinsic high aggressiveness of the tumor. ${ }^{20,21}$ The mainstay for treatment of primary sinonasal mucosal melanomas continues to be the surgical excision, with the endoscopic-assisted approaches that prove to be a safe and feasible procedure alternative to open surgery, with reduced morbidity and 
TABLE 5. KIT mutations in melanoma subtypes reported in the literature.

\begin{tabular}{|c|c|c|c|c|c|}
\hline \multirow[b]{2}{*}{ Reference } & \multicolumn{3}{|c|}{ Mucosal Melanoma } & \multirow[b]{2}{*}{$\begin{array}{l}\text { Acral melanoma, } \\
\text { Frequency (rate) }\end{array}$} & \multirow{2}{*}{$\begin{array}{c}\text { Chronic sun-damage melanoma, } \\
\text { Frequency (rate) }\end{array}$} \\
\hline & Frequency (rate) & $\begin{array}{l}\text { Site, no. of } \\
\text { patients }\end{array}$ & $\begin{array}{l}\text { Exon, no. of } \\
\text { patients }\end{array}$ & & \\
\hline Curtin $^{7}$ & $8 / 38$ (21\%) & NOS & $\begin{array}{l}11(4) \\
13(3) \\
18(1)\end{array}$ & $3 / 28(11 \%)$ & $3 / 18(16.7 \%)$ \\
\hline Antonescu ${ }^{40}$ & $3 / 20(15 \%)$ & AN (3) & $11(3)$ & - & - \\
\hline Rivera $^{39}$ & $4 / 18(22.2 \%)$ & OCA (4) & $\begin{array}{l}11(2) \\
13(2)\end{array}$ & - & - \\
\hline Satzger ${ }^{41}$ & $6 / 37(16 \%)$ & $\begin{array}{c}\text { HN (2) } \\
\text { GU (3) } \\
\text { AN (1) }\end{array}$ & $11(5)$ & - & - \\
\hline Beadling $^{42}$ & $7 / 45(15.6 \%)$ & $\begin{array}{c}\text { HN (3) } \\
\text { AN, GU (4) }\end{array}$ & $\begin{array}{l}11(6) \\
17(1)\end{array}$ & $3 / 13(23 \%)$ & $1 / 58(1.7 \%)^{\star}$ \\
\hline Carvajal $^{46}$ & $12 / 45(27 \%)$ & NOS & NOS & $5 / 22(23 \%)$ & $0 / 13(0 \%)$ \\
\hline Torres-Cabala ${ }^{45}$ & $9 / 52(17 \%)$ & $\begin{array}{c}\text { AN (3) } \\
\text { GU (4) } \\
\text { OCA (1) } \\
\text { OCU (1) }\end{array}$ & $\begin{array}{l}11(6) \\
13(2) \\
17(1)\end{array}$ & $5 / 39(12.8 \%)$ & - \\
\hline Ashida $^{29}$ & $0 / 6(0 \%)$ & - & - & $2 / 22(9 \%)$ & - \\
\hline Handolias ${ }^{43}$ & $6 / 16(37.5 \%)$ & $\begin{array}{l}\text { AN (4) } \\
\text { GU (1) } \\
\text { OC (1) }\end{array}$ & $\begin{array}{l}11(3) \\
17(2) \\
13(1)\end{array}$ & $1 / 16(6 \%)$ & - \\
\hline Kong ${ }^{44}$ & $16 / 167(9.6 \%)$ & NOS & $\begin{array}{l}11(9) \\
13(2) \\
17(4) \\
18(1)\end{array}$ & $23 / 193(11.9 \%)$ & $6 / 29(20.7 \%)$ \\
\hline This report & $4 / 32(12.5 \%)$ & SN (4) & $\begin{array}{l}11(3) \\
18(1)\end{array}$ & - & - \\
\hline
\end{tabular}

Abbreviations: NOS, not otherwise specified; AN, anal; OCA, oral cavity; HN, head and neck; GU, genitourinary tract; OCU, ocular; SN, sinonasal.

${ }^{*}$ Cutaneous melanoma subtype not specified.

comparable results. At the present time, no significant improvement in survival can be obtained by systemic ${ }^{16}$ and local adjuvant treatment in primary sinonasal mucosal melanomas. $^{22-27}$

Although the molecular-driven stepwise transformation of melanocytes has been extensively documented in cuta- neous melanoma, ${ }^{1}$ much less is known about the rarer and more aggressive forms of primary mucosal melanoma, including primary sinonasal mucosal melanomas. We found that primary sinonasal mucosal melanomas are characterized by the occurrence of mutually exclusive somatic mutations of NRAS (22\%) and KIT (12.5\%),

TABLE 6. Treatment of patients with KIT-mutated metastatic melanoma with tyrosine-kinase inhibitors reported in the literature.

\begin{tabular}{|c|c|c|c|c|c|c|c|}
\hline Reference & $\begin{array}{l}\text { No. of } \\
\text { patients }\end{array}$ & Melanoma type & KIT (IHC) & KIT abnormalities & Agent & Dose, mg/d & Clinical response \\
\hline Lutzky ${ }^{47}$ & 1 & Mucosal & + & $\mathrm{K} 642 \mathrm{E}$ & Imatinib & $400-600$ & CR \\
\hline Hodi $^{48}$ & 1 & Mucosal & + & ex $11^{*}$ & Imatinib & 400 & CR \\
\hline Quintas-Cardama ${ }^{49}$ & 1 & Mucosal & + & V560A & Sorafenib & 800 & CR \\
\hline \multirow[t]{3}{*}{ Carvajal $^{46}$} & 5 & Acral and mucosal & + & 3 pts: ex $11^{\dagger}$ & Imatinib & $300-800$ & 3 pts: PR \\
\hline & & & & 1 pt: ex $11^{\ddagger}$ & Imatinib & & 2 pts: SD \\
\hline & & & & 1 pt: ex $13^{\dagger}$ & Imatinib & & \\
\hline Woodman ${ }^{50}$ & 2 & & + & L576P & Dasatinib & 140 & PR \\
\hline Zhu $u^{53}$ & 1 & Mucosal & + & V559A & Sunitinib & 37.5 & PR \\
\hline \multirow[t]{2}{*}{ Kluger $^{51}$} & 2 & Acral and mucosal & + & $1 \mathrm{pt}: \mathrm{K} 642 \mathrm{E}$ & Dasatinib & 140 & 1 pt: PR \\
\hline & & & & 1 pt: ex $11^{\$}$ & Dasatinib & & 1 pt: NR \\
\hline Satzger $^{52}$ & 1 & Mucosal & + & L576P & Imatinib & 400 & SD \\
\hline \multirow[t]{4}{*}{ Handolias ${ }^{43}$} & 4 & Mucosal & + & $1 \mathrm{pt}$ ex $11^{*}$ & Imatinib & 600 & PR \\
\hline & & & & 1 pt: K642E & Imatinib & 400 & PR \\
\hline & & & & 1 pt: L576P & Imatinib & $400-600$ & PD \\
\hline & & & & 1 pt: D820Y & Sorafenib & 400 & SD \\
\hline
\end{tabular}

Abbreviations: IHC, immunohistochemistry; CR, complete response; PR, partial response; SD, stable disease; NR, no response; PD, progressive disease.

*Duplication.

${ }^{\dagger}$ Mutation not otherwise specified.

${ }^{\ddagger}$ Amplification.

$\$$ Deletion. 
associated with amplification of RREBl (100\%), loss of $M Y B(76 \%)$, and variable loss of tumor suppressor genes, including PTEN (48.1\%) and p16/INK4a (55.2\%). These abnormalities might lead to diffuse activation of PI3K/ Akt and RAS-MAPK pathways, as shown by immunostaining for pAkt and pERK. Remarkably, this profile is partially shared by mucosal melanoma from other sites and by AL group. ${ }^{28,29}$

Similarly to other mucosal melanoma and AL/mucosal, primary sinonasal mucosal melanomas lack the V600E mutation in the BRAF gene, which is instead a very common somatic event in nonchronic sun-damage cutaneous melanoma. ${ }^{3,30-32}$ This finding strongly argues against the clinical efficacy of the recently introduced RAF inhibitor in primary sinonasal mucosal melanomas. ${ }^{33}$ Notably, we detected a D594G substitution of the BRAF gene in only 1 case. This mutation has been previously characterized in melanoma cell lines and compared to the V600E mutant, D594G is a low-activity mutant that signals through CRAF and is sensitive to Sorafenib. ${ }^{34}$

NRAS mutations were found in $22 \%$ of cases and involved codons 12,13 , and 61 . This mutation rate is similar to nonchronic sun-damage melanoma. ${ }^{2}$ Recently, NRAS mutations have also been reported in mucosal melanoma arising from different sites. ${ }^{31,35}$ Although molecular strategies targeting mutant RAS have not been very successful, ${ }^{36,37}$ recently it has been reported that efficacious targeting of NRAS-driven cutaneous melanomas can be obtained by simultaneous silencing of multiple RAS effectors, including BRAF, CRAF, and PIK3CA. ${ }^{38}$

In keeping with recent data that showed that activating mutations of the KIT gene occur with variable frequency in mucosal melanoma and cutaneous melanoma (Table $5),{ }^{7,29,39-46}$ we found KIT mutations in $12.5 \%$ of primary sinonasal mucosal melanomas cases. KIT mutations have been observed in $9.6 \%$ of mucosal melanoma and represented an adverse prognostic factor for overall survival. ${ }^{44}$ Interestingly, KIT mutated mucosal melanomas are sensitive to tyrosine kinase inhibitors (TKis) (Table 6). ${ }^{43,46-53}$ All the KIT mutations found in our cohort of primary sinonasal mucosal melanomas are activating and located in the juxta-membrane region (exon 11; W557C, K558E, and L576P) or in the TK2 domain (exon 18; S864F) of the tyrosine-kinase receptor. $\mathrm{K} 558 \mathrm{E}$ and $\mathrm{S} 864 \mathrm{~F}$ mutations are very rare in human cancers. ${ }^{54,55}$ Substitutions in codon 557 are very common and sensitive to TKis in patients with gastrointestinal stromal tumors (GIST), ${ }^{56}$ although the specific W557C substitution has been detected in only 2 patients with GIST $^{57}$ and in a single case of intracranial germinoma. ${ }^{58}$ L576P mutation is the most common mutation in melanoma and shows sensitivity to $\mathrm{TKi},{ }^{40}$ especially to dasatinib. ${ }^{50}$ In GIST, KIT mutations are commonly associated with protein overexpression by immunohistochemistry ${ }^{59,60}$; however, protein overexpression alone is not sufficient to predict clinical response to TKi and the selection of candidates for TKi should be based on mutational status of the KIT gene. ${ }^{61}$ Similarly, KIT overexpression in melanomas cannot predict sensitivity to $\mathrm{TKi}^{62}$ In our series, the immunohistochemical staining for KIT has low sensitivity $(75 \%)$, very low specificity $(42.8 \%)$, poor positive predictive value $(15.8 \%)$, and significant negative predictive value $(92.3 \%)$ in detecting mutations.
Significantly, we observed that all primary sinonasal mucosal melanomas were identified by using a novel FISH panel which include 3 locus-specific identifier (RREB 1, MYB, and CCND1) genes. In particular primary sinonasal mucosal melanomas, similarly to the cutaneous counterpart, shows a high frequency of gain of $6 \mathrm{p} 25$ and loss of 6q23. Conversely, gain of 11q13 (CCND1), which is reported in more than $30 \%$ of cutaneous melanomas including the AL/mucosal subtype, ${ }^{8,63}$ was not observed in primary sinonasal mucosal melanomas. However, overexpression of CCNDI protein ( $>$ score 1) was present in $65.6 \%$ of primary sinonasal mucosal melanoma cases. Although limited to a single cell line of metastatic melanoma overexpressing cyclin $\mathrm{D} 1$, silencing of the CCND1 gene by antisense oligonucleotides resulted in significant suppression of tumor growth even in the absence of gene amplification. ${ }^{64}$ Although data require further validation, they could help identify a novel targeting strategy for primary sinonasal mucosal melanomas.

Data on the role of tumor suppressor genes in mucosal melanoma transformation and progression are inconclusive. We report that among tumor suppressor genes, a significant fraction of primary sinonasal mucosal melanomas have lost PTEN (48.1\%) and p16 (55.2\%), with total absence of the protein in $33.3 \%$ and $6.8 \%$ of the cases, respectively. Loss of PTEN together with activating mutations of PIK3CA are the major molecular events leading to the hyperactivation of PI3K-Akt pathway in a wide variety of human neoplasms. ${ }^{65}$ In our cohort of primary sinonasal mucosal melanomas, the diffuse hyperactivation of PI3K-Akt pathway, as proved by the expression of pAkt (recognizing the phosphorylated Ser473 residue), ${ }^{66}$ was found in $89.7 \%$ of cases. This result, which can be explained in a fraction of cases by PTEN loss, is not dependent on activating mutations of PIK3CA. Although these findings require further investigation at the genetic and epigenetic levels, they clearly indicate that activation of PI3K-Akt might sustain primary sinonasal mucosal melanomas progression. Strategies to inhibit PI3K-Akt-mTOR pathway at multiple levels are currently in clinical trials and might represent a promising tool also for melanomas. ${ }^{67}$ Our findings indicate that the immunohistochemical demonstration of pAkt expression and PTEN loss might identify responders to PI3K-Akt-mTOR inhibitors.

To our knowledge, this is the largest series of primary sinonasal mucosal melanomas subjected to a comprehensive analysis of the molecular abnormalities in oncogenes and tumor suppressor genes. We found that primary sinonasal mucosal melanomas are characterized by a complex array of abnormalities leading to diffuse activation of the PI3K/Akt and RAS-MAPK pathways. The occurrence of these abnormalities does not represent a prognostic factor in terms of patient survival; however, large-scale studies are mandatory to this end. Significantly, early somatic events (KIT, NRAS, and BRAF mutations) are observed only in a relatively small fraction of primary sinonasal mucosal melanomas. This suggests that additional, unknown abnormalities might drive or cooperate in sunlight-independent melanoma genesis. On the other hand, the consistent finding of KIT protein expression in primary sinonasal mucosal melanomas indicate that the 
activation of PI3K/Akt and RAS-MAPK pathways might also rely on ligand-dependent activation of this receptor. On the evidence that effective and durable molecular targeting approaches require inhibition of multiple pathway check points, ${ }^{68,69}$ our data might have implications for the development of tailored therapies for primary sinonasal mucosal melanomas.

\section{Acknowledgements}

The authors thank Dr. Alberto Zaniboni (Fondazione Poliambulanza, Brescia, Italy) for helpful suggestion; to Paola Bossini and Laura Fappani (Department of Pathology, Brescia) for technical support.

\section{REFERENCES}

1. Miller AJ, Mihm MC Jr. Melanoma. N Engl J Med 2006;355:51-65.

2. Dahl C, Guldberg P. The genome and epigenome of malignant melanoma. APMIS 2007;115:1161-1176.

3. Curtin JA, Fridlyand J, Kageshita T, et al. Distinct sets of genetic alterations in melanoma. N Engl J Med 2005;353:2135-2147.

4. Davies H, Bignell GR, Cox C, et al. Mutations of the BRAF gene in human cancer. Nature 2002;417:949-954.

5. Lee JH, Choi JW, Kim YS. Frequencies of BRAF and NRAS mutations are different in histological types and sites of origin of cutaneous melanoma: a meta-analysis. Br J Dermatol 2011;164:776-784.

6. Wu H, Goel V, Haluska FG. PTEN signaling pathways in melanoma. Oncogene 2003;22:3113-3122.

7. Curtin JA, Busam K, Pinkel D, Bastian BC. Somatic activation of KIT in distinct subtypes of melanoma. J Clin Oncol 2006;24:4340-4346.

8. Bastian BC. Understanding the progression of melanocytic neoplasia using genomic analysis: from fields to cancer. Oncogene 2003;22:3081-3086.

9. Smalley KS, Contractor R, Nguyen TK, et al. Identification of a novel subgroup of melanomas with KIT/cyclin-dependent kinase-4 overexpression. Cancer Res 2008;68:5743-5752.

10. Vidwans SJ, Flaherty KT, Fisher DE, Tenenbaum JM, Travers MD, Shrager J. A melanoma molecular disease model. PLoS One 2011;6: e18257.

11. Dauer EH, Lewis JE, Rohlinger AL, Weaver AL, Olsen KD. Sinonasal melanoma: a clinicopathologic review of 61 cases. Otolaryngol Head Neck Surg 2008;138:347-352.

12. Roth TN, Gengler C, Huber GF, Holzmann D. Outcome of sinonasal melanoma: clinical experience and review of the literature. Head Neck 2010; 32:1385-1392.

13. Moreno MA, Roberts DB, Kupferman ME, et al. Mucosal melanoma of the nose and paranasal sinuses, a contemporary experience from the M. D. Anderson Cancer Center. Cancer 2010;116:2215-2223.

14. Gerami P, Jewell SS, Morrison LE, et al. Fluorescence in situ hybridization (FISH) as an ancillary diagnostic tool in the diagnosis of melanoma. Am J Surg Pathol 2009;33:1146-1156.

15. Jethanamest D, Vila PM, Sikora AG, Morris LG. Predictors of Survival in Mucosal Melanoma of the Head and Neck. Ann Surg Oncol 2011;18: 2748-2756.

16. Moreno MA, Hanna EY. Management of mucosal melanomas of the head and neck: did we make any progress? Curr Opin Otolaryngol Head Neck Surg 2010;18:101-106.

17. Gerami P, Mafee M, Lurtsbarapa T, Guitart J, Haghighat Z, Newman M. Sensitivity of fluorescence in situ hybridization for melanoma diagnosis using RREB1, MYB, Cep6, and 11q13 probes in melanoma subtypes. Arch Dermatol 2010;146:273-278.

18. Smalley KS. Understanding melanoma signaling networks as the basis for molecular targeted therapy. J Invest Dermatol 2010;130:28-37.

19. Franchi A, Alos L, Gale N, et al. Expression of p16 in sinonasal malignant melanoma. Virchows Arch 2006;449:667-672.

20. Hussein MR. Extracutaneous malignant melanomas. Cancer Invest 2008; 26:516-534.

21. Patrick RJ, Fenske NA, Messina JL. Primary mucosal melanoma. J Am Acad Dermatol 2007;56:828-834.

22. Lund VJ, Howard DJ, Harding L, Wei WI. Management options and survival in malignant melanoma of the sinonasal mucosa. Laryngoscope 1999;109(2 Pt 1):208-211.

23. Krengli M, Masini L, Kaanders JH, et al. Radiotherapy in the treatment of mucosal melanoma of the upper aerodigestive tract: analysis of 74 cases. A Rare Cancer Network study. Int J Radiat Oncol Biol Phys 2006;65: 751-759.

24. Krengli M, Jereczek-Fossa BA, Kaanders JH, Masini L, Beldì D, Orecchia $\mathrm{R}$. What is the role of radiotherapy in the treatment of mucosal melanoma of the head and neck? Crit Rev Oncol Hematol 2008;65:121-128.
25. Benlyazid A, Thariat J, Temam S, et al. Postoperative radiotherapy in head and neck mucosal melanoma: a GETTEC study. Arch Otolaryngol Head Neck Surg 2010;136:1219-1225.

26. Yanagi T, Mizoe JE, Hasegawa A, et al. Mucosal malignant melanoma of the head and neck treated by carbon ion radiotherapy. Int $J$ Radiat Oncol Biol Phys 2009;74:15-20.

27. Zenda S, Kawashima M, Nishio T, et al. Proton beam therapy as a nonsurgical approach to mucosal melanoma of the head and neck: a pilot study. Int J Radiat Oncol Biol Phys 2011;81:135-139.

28. Smalley KS, Sondak VK, Weber JS. c-KIT signaling as the driving oncogenic event in sub-groups of melanomas. Histol Histopathol 2009;24 643-650.

29. Ashida A, Takata M, Murata H, Kido K, Saida T. Pathological activation of KIT in metastatic tumors of acral and mucosal melanomas. Int J Cancer 2009; 124:862-868.

30. Maldonado JL, Fridlyand J, Patel H, et al. Determinants of BRAF mutations in primary melanomas. J Natl Cancer Inst 2003;95:1878-1890.

31. Wong CW, Fan YS, Chan TL, et al. BRAF and NRAS mutations are uncommon in melanomas arising in diverse internal organs. J Clin Pathol 2005;58:640-644.

32. Edwards RH, Ward MR, Wu H, et al. Absence of BRAF mutations in UVprotected mucosal melanomas. J Med Genet 2004;41:270-272.

33. Bollag G, Hirth P, Tsai J, et al. Clinical efficacy of a RAF inhibitor needs broad target blockade in BRAF-mutant melanoma. Nature 2010;467: 596-599.

34. Smalley KS, Xiao M, Villanueva J, et al. CRAF inhibition induces apoptosis in melanoma cells with non-V600E BRAF mutations. Oncogene 2009; 28:85-94.

35. Sekine S, Nakanishi Y, Ogawa R, Kouda S, Kanai Y. Esophageal melanomas harbor frequent NRAS mutations unlike melanomas of other mucosal sites. Virchows Arch 2009;454:513-517.

36. Diaz-Flores E, Shannon K. Targeting oncogenic Ras. Genes Dev 2007;21: 1989-1992.

37. Downward J. Targeting RAS signalling pathways in cancer therapy. Nat Rev Cancer 2003;3:11-22.

38. Jaiswal BS, Janakiraman V, Kljavin NM, et al. Combined targeting of BRAF and CRAF or BRAF and PI3K effector pathways is required for efficacy in NRAS mutant tumors. PLoS One 2009;4:e5717.

39. Rivera RS, Nagatsuka H, Gunduz M, et al. C-kit protein expression correlated with activating mutations in KIT gene in oral mucosal melanoma. Virchows Arch 2008;452:27-32.

40. Antonescu CR, Busam KJ, Francone TD, et al. L576P KIT mutation in anal melanomas correlates with KIT protein expression and is sensitive to specific kinase inhibition. Int J Cancer 2007;121:257-264.

41. Satzger I, Schaefer T, Kuettler U, et al. Analysis of c-KIT expression and KIT gene mutation in human mucosal melanomas. Br J Cancer 2008;99; 2065-2069.

42. Beadling C, Jacobson-Dunlop E, Hodi FS, et al. KIT gene mutations and copy number in melanoma subtypes. Clin Cancer Res 2008;14: 6821-6828.

43. Handolias D, Hamilton AL, Salemi R, et al. Clinical responses observed with imatinib or sorafenib in melanoma patients expressing mutations in KIT. Br J Cancer 2010;102:1219-1223.

44. Kong Y, Si L, Zhu Y, et al. Large-scale analysis of KIT aberrations in Chinese patients with melanoma. Clin Cancer Res 2011;17:1684-1691.

45. Torres-Cabala CA, Wang WL, Trent J, et al. Correlation between KIT expression and KIT mutation in melanoma: a study of 173 cases with emphasis on the acral-lentiginous/mucosal type. Mod Pathol 2009;22: 1446-1456.

46. Carvajal RD, Chapman PB, Wolchok JD, et al. A phase II study of imatinib mesylate (IM) for patients with advanced melanoma harboring somatic alterations of KIT. J Clin Oncol 2009;27(suppl):Abstract 9001.

47. Lutzky J, Bauer J, Bastian BC. Dose-dependent, complete response to imatinib of a metastatic mucosal melanoma with a K642E KIT mutation. Pigment Cell Melanoma Res 2008;21:492-493.

48. Hodi FS, Friedlander P, Corless CL, et al. Major response to imatinib mesylate in KIT-mutated melanoma. J Clin Oncol 2008;26:2046-2051.

49. Quintás-Cardama A, Lazar AJ, Woodman SE, Kim K, Ross M, Hwu P. Complete response of stage IV anal mucosal melanoma expressing KIT Val560Asp to the multikinase inhibitor sorafenib. Nat Clin Pract Oncol 2008;5:737-740.

50. Woodman SE, Trent JC, Stemke-Hale K, et al. Activity of dasatinib against L576P KIT mutant melanoma: molecular, cellular, and clinical correlates. Mol Cancer Ther 2009;8:2079-2085.

51. Kluger HM, Dudek AZ, McCann C, et al. A phase 2 trial of dasatinib in advanced melanoma. Cancer 2011;117:2202-2208.

52. Satzger I, Küttler U, Völker B, Schenck F, Kapp A, Gutzmer R. Anal mucosal melanoma with KIT-activating mutation and response to imatinib therapy-case report and review of the literature. Dermatology 2010;220: 77-81.

53. Zhu Y, Si L, Kong Y, et al. Response to sunitinib in Chinese KIT-mutated metastatic mucosal melanoma. J Clin Oncol 2009;27(suppl): Abstract e20017.

54. Tate G, Tajiri T, Suzuki T, Mitsuya T. Mutations of the KIT gene and loss of heterozygosity of the PTEN region in a primary malignant melanoma 
arising from a mature cystic teratoma of the ovary. Cancer Genet Cytogenet 2009; 190:15-20.

55. Daniotti M, Ferrari A, Frigerio S, et al. Cutaneous melanoma in childhood and adolescence shows frequent loss of INK4A and gain of KIT. $J$ Invest Dermatol 2009; 129:1759-1768.

56. Lasota J, Miettinen M. Clinical significance of oncogenic KIT and PDGFRA mutations in gastrointestinal stromal tumours. Histopathology 2008;53:245-266.

57. Maurel J, Martins AS, Poveda A, et al. Imatinib plus low-dose doxorubicin in patients with advanced gastrointestinal stromal tumors refractory to high-dose imatinib: a phase I-II study by the Spanish Group for Research on Sarcomas. Cancer 2010;116:3692-3701.

58. Sakuma Y, Sakurai S, Oguni S, Satoh M, Hironaka M, Saito K. c-kit gene mutations in intracranial germinomas. Cancer Sci 2004;95:716-720.

59. Zheng S, Chen LR, Wang HJ, Chen SZ. Analysis of mutation and expression of c-kit and PDGFR-alpha gene in gastrointestinal stromal tumor. Hepatogastroenterology 2007;54:2285-2290.

60. Miettinen M, Lasota J. Gastrointestinal stromal tumors-definition, clinical, histological, immunohistochemical, and molecular genetic features and differential diagnosis. Virchows Arch 2001;438:1-12.

61. Heinrich MC, Corless CL, Demetri GD, et al. Kinase mutations and imatinib response in patients with metastatic gastrointestinal stromal tumor. $J$ Clin Oncol 2003;21:4342-4349.
62. Alexis JB, Martinez AE, Lutzky J. An immunohistochemical evaluation of c-kit (CD-117) expression in malignant melanoma, and results of imatinib mesylate (Gleevec) therapy in three patients. Melanoma Res 2005; 15 : 283-285.

63. Gerami P, Pouryazdanparast P, Vemula S, Bastian BC. Molecular analysis of a case of nevus of ota showing progressive evolution to melanoma with intermediate stages resembling cellular blue nevus. Am J Dermatopathol 2010;32:301-305.

64. Sauter ER, Yeo UC, von Stemm A, et al. Cyclin D1 is a candidate oncogene in cutaneous melanoma. Cancer Res 2002;62:3200-3206.

65. Hennessy BT, Smith DL, Ram PT, Lu Y, Mills GB. Exploiting the PI3K/ AKT pathway for cancer drug discovery. Nat Rev Drug Discov 2005;4: 988-1004.

66. Stephens L, Williams R, Hawkins P. Phosphoinositide 3-kinases as drug targets in cancer. Curr Opin Pharmacol 2005;5:357-365.

67. Aziz SA, Jilaveanu LB, Zito C, et al. Vertical targeting of the phosphatidylinositol-3 kinase pathway as a strategy for treating melanoma. Clin Cancer Res 2010;16:6029-6039.

68. Friedlander P, Hodi FS. Advances in targeted therapy for melanoma. Clin Adv Hematol Oncol 2010;8:619-627.

69. Smalley KS, Nathanson KL, Flaherty KT. Genetic subgrouping of melanoma reveals new opportunities for targeted therapy. Cancer Res 2009;69: 3241-3244. 